\title{
Implementation of the National Incident Management System (NIMS)/Incident Command System (ICS) in the Federal Radiological Monitoring and Assessment Center (FRMAC) - Emergency Phase
}

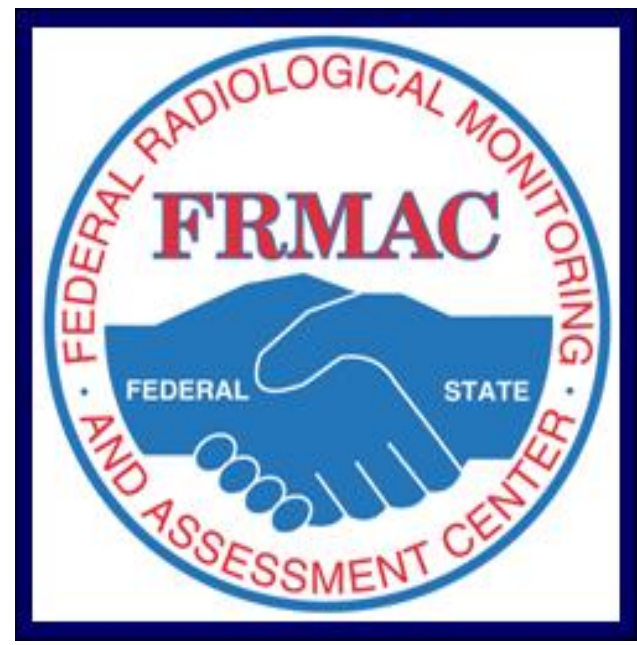

April 2007

National Security Technologies, LLC Remote Sensing Laboratory Nellis Operations 


\title{
Implementation of the National Incident Management System (NIMS) / Incident Commar System (ICS) in the Federal Radiological Monitoring and Assessment Center (FRMAC) - Emergency Phase
}

\author{
Colleen T. O'Laughlin, Program Manager \\ Consequence Management/Federal Radiological Monitoring and Assessment Center \\ U.S. Department of Energy, National Nuclear Security Administration \\ Nevada Site Office, Las Vegas, Nevada
}

Roger C. Thompson, Emergency Response Team Lead

Assistant Manager Nuclear Security

U.S. Department of Energy, National Nuclear Security Administration

Nevada Site Office, Las Vegas, Nevada

\begin{tabular}{c}
\hline Deborah A. Wilber, Director \\
Office of Emergency Response \\
U.S. Department of Energy \\
National Nuclear Security Administration \\
Headquarters Office of Emergency Operations \\
Washington, D.C. \\
\hline Robert T. Augdahl \\
Derivative Classifier \\
National Security Technologies, LLC
\end{tabular}

This work was done by National Security Technologies, LLC, under Contract No. DE-AC52-06NA25946 with the U.S. Department of Energy. 


\section{ACRONYMS}

$\begin{array}{ll}\text { AMS } & \text { Arial Measuring System } \\ \text { DHS } & \text { U.S. Department of Homeland Security } \\ \text { DOE } & \text { U.S. Department of Energy } \\ \text { EOC } & \text { Emergency Operation Center } \\ \text { FCO } & \text { Federal Coordinating Officer } \\ \text { FRMAC } & \text { Federal Radiological Monitoring and Assessment Center } \\ \text { IAP } & \text { Incident Action Plan } \\ \text { GIS } & \text { Geographical Information System } \\ \text { ICS } & \text { Incident Command System } \\ \text { INS } & \text { Incident of National Significance } \\ \text { JFO } & \text { Joint Field Office } \\ \text { JIC } & \text { Joint Information Center } \\ \text { NARAC } & \text { National Atmospheric Release Advisory Center } \\ \text { NIMS } & \text { National Incident Management System } \\ \text { NRP } & \text { National Response Plan } \\ \text { NUC } & \text { NRP Nuclear/Radiological Incident Annex } \\ \text { PFO } & \text { Principal Federal Official } \\ \text { RAP } & \text { Radiological Assistance Program } \\ \text { SEO } & \text { Senior Energy Official } \\ \text { SSA } & \text { Senior Science Advisor } \\ \text { UC } & \text { Unified Command }\end{array}$




\section{Implementation of the National Incident Management Systems (NIMS)/ Incident Command System (ICS) in Federal Radiological Monitoring and Assessment Center (FRMAC) - Emergency Phase}

\subsection{Introduction}

Homeland Security Presidential Directive HSPD-5 requires all federal departments and agencies to adopt a National Incident Management System (NIMS)/Incident Command System (ICS) and use it in their individual domestic incident management and emergency prevention, preparedness, response, recovery, and mitigation programs and activities, as well as in support of those actions taken to assist state and local entities. ${ }^{1}$ This system provides a consistent nationwide template to enable federal, state, local, and tribal governments, private-sector, and nongovernmental organizations to work together effectively and efficiently to prepare for, prevent, respond to, and recover from domestic incidents, regardless of cause, size, or complexity, including acts of catastrophic terrorism. This document identifies the operational concepts of the Federal Radiological Monitoring and Assessment Center's (FRMAC) implementation of the NIMS/ICS response structure under the National Response Plan (NRP). The construct identified here defines the basic response template to be tailored to the incident-specific response requirements.

FRMAC's mission to facilitate interagency environmental data management, monitoring, sampling, analysis, and assessment and link this information to the planning and decision staff clearly places the FRMAC in the Planning Section. FRMAC is not a mitigating resource for radiological contamination but is present to conduct radiological impact assessment for public dose avoidance. Field monitoring is a fact-finding mission to support this effort directly. Decisions based on the assessed data will drive public protection and operational requirements. This organizational structure under NIMS is focused by the mission responsibilities and interface requirements following the premise to provide emergency responders with a flexible yet standardized structure for incident response activities.

The coordination responsibilities outlined in the NRP are based on the NIMS/ICS construct and Unified Command (UC) for management of a domestic incident. The NRP Nuclear/Radiological Incident Annex (NUC) further provides requirements and protocols for coordinating federal government capabilities to respond to nuclear/radiological Incidents of National Significance (INS) and other radiological incidents. When a FRMAC is established, it operates under the parameters of NIMS as defined in the NRP. FRMAC and its operations have been modified to reflect NIMS/ICS concepts and principles and to facilitate working in a Unified Command structure. FRMAC is established at or near the scene of the incident to coordinate radiological monitoring and assessment and is established in coordination with the U.S. Department of Homeland Security (DHS); the coordinating agency; other federal agencies; and state, local, and tribal authorities. ${ }^{2}$ However, regardless of the coordinating agency designation, U.S. Department of Energy (DOE) coordinates radiological monitoring and assessment activities for the initial phases of the offsite federal incident response through the Radiological Assistance Program (RAP)

\footnotetext{
${ }^{1}$ National Incident Management System, March 2007

2 National Response Plan, December 2004 (Nuc/Rad Annex)
} 
and FRMAC assets. Monitoring and assessment data are managed by FRMAC in an accountable, secure, and retrievable format. Monitoring data interpretations, including exposure rate contours, dose projections, and any requested radiological assessments are to be provided to the DHS; to the coordinating agency; and to state, local, and tribal government agencies.

\subsection{Nuclear/Radiological Incident Annex (NUC)}

The Nuclear/Radiological Incident Annex describes how the coordinating agencies and cooperating agencies support the DHS overall response to a nuclear/radiological INS. Following NIMS/ICS, the FRMAC response will be scaled according to the magnitude of the incident. The coordinating agency and a number of cooperating agencies may change, but the FRMAC response structure will remain consistent. In a response that does not rise to the level of an INS, the FRMAC will report to the Senior Federal Official of the coordinating agency.

\subsection{Concepts and Principles}

ICS provides a flexible core mechanism for coordinated and collaborative incident management while imposing the least possible disruption on existing systems and processes. Organizational planning and training will facilitate integration of concepts and principles into FRMAC operations. There are certain proven concepts within ICS that contribute to an effective and efficient response, and will be included in FRMAC planning:

- $\quad$ Common Terminology. Organizational and resource descriptions and position titles.

- Modular Organization. Establishment and expansion on the requirements of the incident (phased response).

- Management by Objective and reliance on an Incident Action Plan. Common understanding of response planning process of objectives and priorities.

- Span of control. Each supervisor should have between three and seven elements within his command.

- Lines of authority. Each individual should be responsible to one, and only one, supervisor.

- Integrated Communication. Use of a common communication plan and interoperable communication process and architectures for voice and data.

- $\quad$ Unified Command. Allows agencies with different legal, geographic, and functional authorities and responsibilities to work together effectively without affecting individual agency authority, responsibility, or accountability.

The FRMAC structure has historically followed the concepts that are central to the NIMS. Minor organizational and operational changes were required to adhere to the NIMS construct. 


\subsection{NIMS Command and Management}

During an INS, a DHS Principal Federal Official (PFO) and Federal Coordinating Officer (FCO) will coordinate overall federal incident management and assistance activities. The basic NIMS framework is shown in Figure 1. A DOE Senior Federal Official (SFO) would represent the coordinating agency in the Joint Field Office (JFO). The DOE SFO enables the effective and efficient coordination of DOE incident-related prevention, preparedness, response, and recovery actions. A Senior Energy Official (SEO) will represent DOE assets in the UC coordination group and support them with statutory authorities and functional responsibilities. FRMAC will provide Liaison Officers as required to management centers to coordinate requests, information, and data products between the FRMAC, and UC. Liaison Officers are technical FRMAC representatives who provide interpretation and explanation of information concerning FRMAC and provided data products.

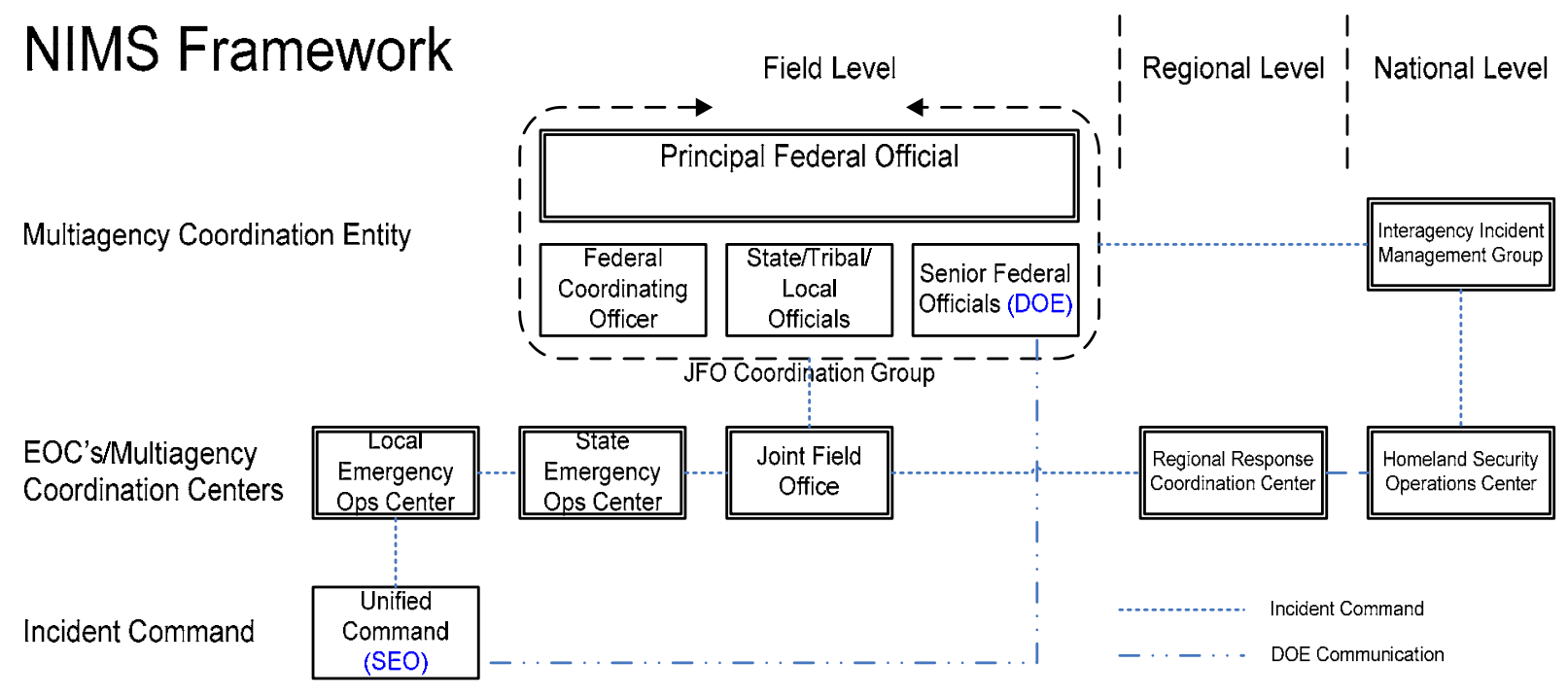

Figure 1. Basic NIMS Framework

\subsection{UC and FRMAC.}

It is assumed that any incident that will require a FRMAC will have expanded into a multiagency response operating under a UC structure. A small, single ICS response will most likely be handled by a DOE RAP team. If the situation on scene exceeds the capability of the RAP team, or involves multiple agencies, FRMAC assistance will be requested.

UC is a team effort that allows all agencies with jurisdictional responsibilities for an incident, either geographical or functional, to participate in the management of the incident. The basic ICS structure is depicted in Figure 2. The UC must develop and implement a common set of incident objectives and strategies that all can subscribe to, without losing or abdicating agency authority, responsibility, or accountability. Action requests and priorities are provided by the UC to FRMAC in an Incident Action Plan (IAP). The most 
senior official represented in the UC with decision-making powers and authority to speak on behalf of the FRMAC will be the SEO. The SEO will be appointed by National Nuclear Security Administration NA-42, but may be the RAP Team Leader or FRMAC Director until a SEO is designated.

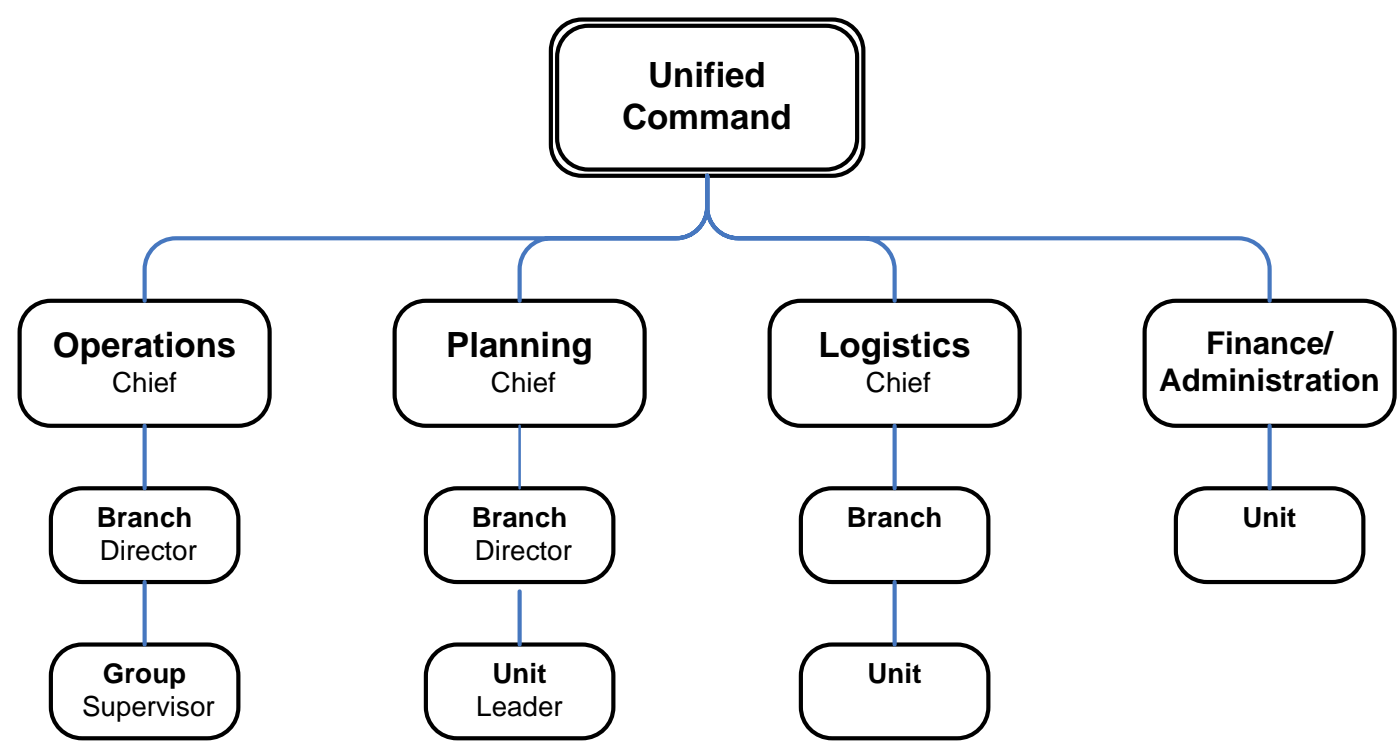

Figure 2. Basic ICS Structure

The Planning Section is responsible for collection, evaluation and dissemination of tactical/technical information pertaining to the incident. Technical units are established under NIMS when there are requirements to coordinate and manage large volumes of environmental sampling and/or analytical data from multiple sources in the context of certain complex incidents involving radiological hazards. ${ }^{3}$ FRMAC's mission falls under the definition of an Environmental Unit in the Planning Section "to facilitate interagency environmental data management, monitoring, sampling, analysis and assessment”. FRMAC will become a branch of the Planning Section with supporting technical units. The FRMAC Director and Senior Science Advisor will be supporting members of the Planning Section of the UC. The FRMAC Director provides direct support to the Planning Section Chief with operational authority for the FRMAC operations. FRMAC, as a branch of the Planning Section, will provide environmental data management, monitoring, sampling, analysis, maps, and other assessment products pertaining to the incident as directed by the IAP. The FRMAC staff in the Planning Section will support the preparation of the IAP.

\footnotetext{
${ }^{3}$ National Incident Management System Rev2, Tab 3, March 2007
} 


\subsection{FRMAC Branch and Technical Units.}

The FRMAC operates in the Planning Section as a branch in one primary location. Due to space requirements, this location may not be in the same place as the Planning Section Chief. Forward monitoring/staging areas may be established to facilitate field monitoring in areas at a long distance from the FRMAC. The FRMAC Director will physically locate with the Planning Section Chief, but he will continue to have operational responsibility for the FRMAC. The FRMAC Deputy Director will manage the unit's operations reporting to the Director. The FRMAC Unit structure will follow the guidelines defined in the FRMAC Operations Manual. Figure 3 presents the basic FRMAC Branch and Unit Structure within the NIMS framework.

FRMAC liaisons are required in the UC and in state EOCs and possibly local coordinating centers (i.e., EOCs). Technical Liaisons for Aerial Measuring System (AMS) and other FRMAC units may be required in other areas such as the Operations and Logistics Sections. All liaisons work under the direction of the FRMAC Director. Liaisons such as in the Operations and Logistics Sections will coordinate requests from the section, coordinate actions FRMAC may require in the areas of responsibility of the Section, and coordinate information and data products between the sections with the Section Chief and representatives.

The FRMAC Public Information Office (PIO) will be in the Joint Information Center (JIC), or in the UC if there is no JIC supporting the FRMAC public information exchange.

Some FRMAC communications will be within the Communications Unit of the Logistics Section Service Branch. While the job of the FRMAC Communications Unit is clearly defined to only provide support to FRMAC, the coordination with other agency communications networks in the incident is so critical that they must be converged with and report to the head of the ICS Communications Unit within the Logistics Section.

FRMAC logistics will be managed by a logistics unit leader. A logistics representative from FRMAC will be located in the Support Branch of the Logistics Section and that individual will support all aspects of the support mission.

While there is a Health and Safety Officer position identified within the UC staff, the FRMAC Health and Safety Unit should answer directly to the FRMAC Director. The FRMAC Director has the ultimate responsibility for the safety of the FRMAC responders. A FRMAC Health and Safety Liaison will be assigned to the UC staff to work with the UC Health and Safety Officer and report to the FRMAC Health and Safety Officer.

The AMS mission will remain within the FRMAC with a FRMAC Liaison assigned in the Air Operations Branch of the Operations Section. The AMS mission is assigned by the Monitoring Manager and is solely to gather information about the incident. A FRMAC Liaison in the Operations Section will support aviation tactical responsibilities when conducting mission assignments. 


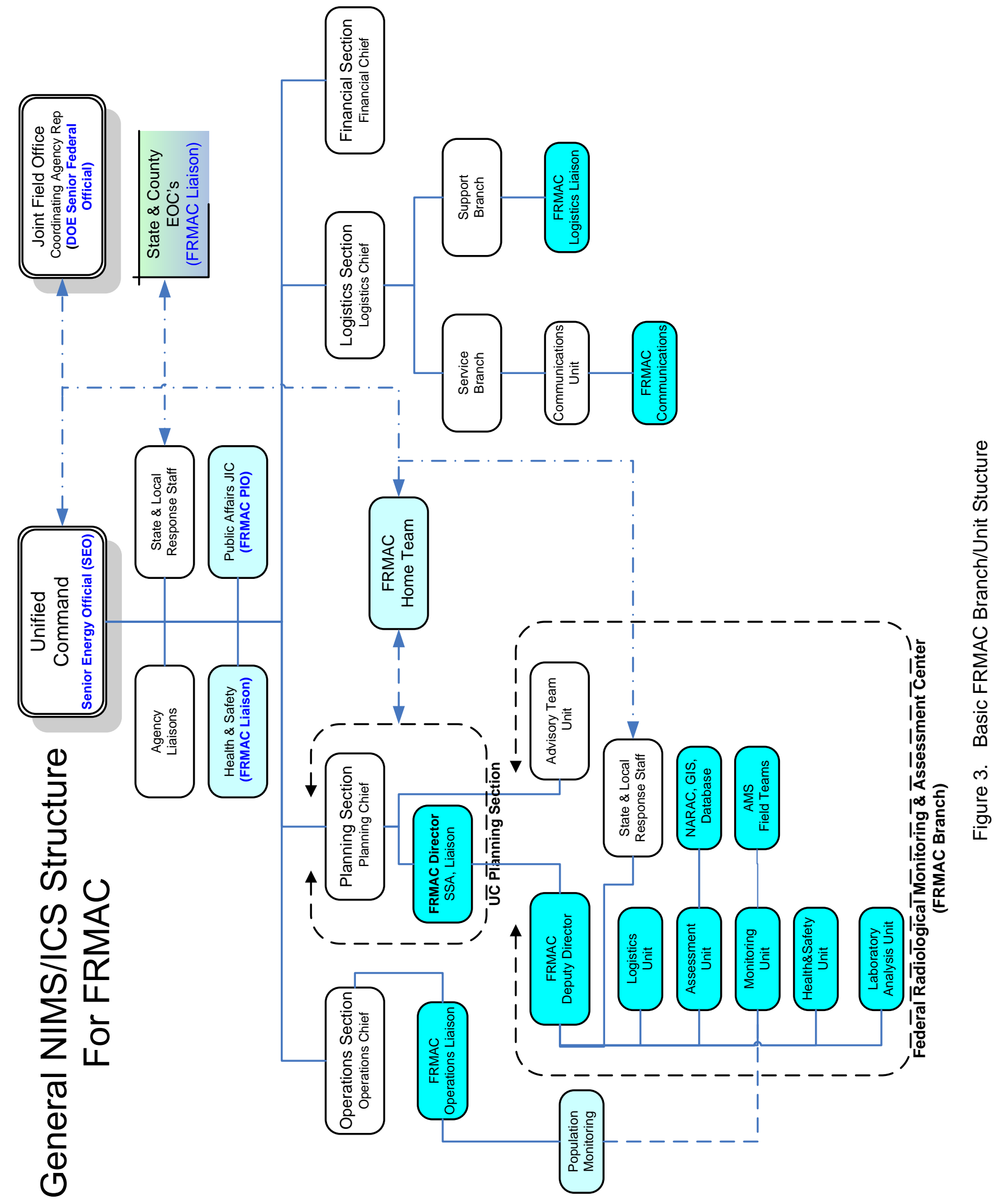

